\title{
An Inexpensive Method of Quality Assessment in Anastomosis Workshops
}

\author{
Maj CA J P Royle \\ MB, FRCS, RAMC \\ Honorary Senior Registrar
}

\section{RKS Phillips}

MS, FRCS

Consultant Surgeon

Surgical Department, St Mark's Hospital, City Road, London

SUMMARY: A method of comparing the quality of intestinal anastomoses performed in craft workshops is described, के The equipment is readily available in any hospital, inexpensive and requires no technical construction. The apparatus $\overrightarrow{0}$ accurately measures the intraluminal pressure at the first sign of anastomotic leak and a method of deriving the wall $\vec{\overrightarrow{ }}$ tension is explained. Calculation of wall tension at the point of failure allows comparison of anastomoses of different $\overrightarrow{\mathcal{E}}$ size. An instructor can therefore monitor the improvement of an individual trainee or rank a class according to the quality of their anastomoses.

\section{Introduction}

Military surgical doctrine still advocates universal exteriorisation or proximal faecal diversion for colonic injury on the battlefield (1). Civilian management of colonic trauma now favours selective primary repair or resection and anastomosis $(2,3)$. As part of a reappraisal of the colonic injury in war an anastomotic workshop study has been devised to assess a new colonic anastomotic technique using disposable skin staples (4). The study involves introducing surgeons to the new technique and recording the quality of their first attempt at an anastomosis in a portable craft workshop.

The method described is not new (5) and determination of anastomotic bursting pressure has been

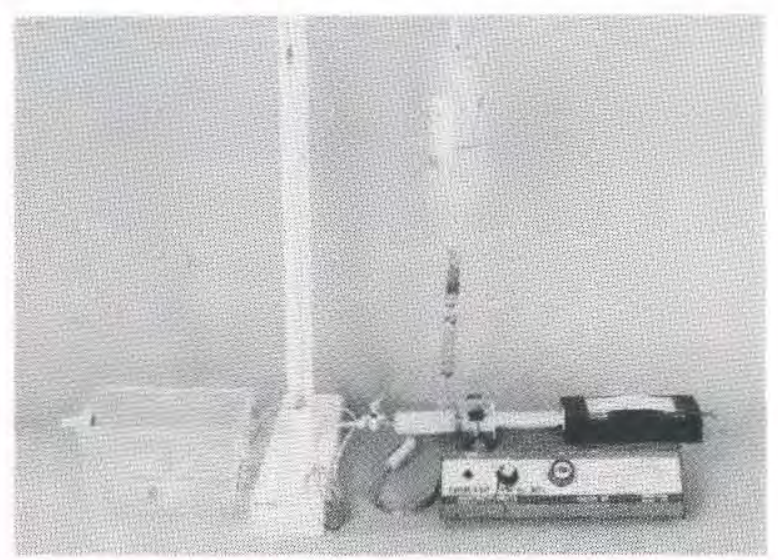

Fig 1. Photograph of assembled equipment illustrating CVP manometer connected to Polyfusor infusion bag and $60 \mathrm{ml}$ syringe via three way tap and the 'venous' end ready for insertion into lumen of anastomosis prior to immersion in water bath. Note opening in top of polyfusor infusion bag and removal of 'Luer' lock connection from venous end of CVP manometer set.

widely used as a measure of intestinal wound healing $(6,7)$.

Craft workshops are becoming an increasingle important part of surgical training (8) but performanc్ is usually determined by subjective assessment which 6 often left to the trainee. Objective measurement ot performance enhances any educational endeavour. ThP study evaluates a simple, inexpensive method $\frac{\mathbb{9}}{9} \mathrm{O}$ providing objective performance data in a cra $\mathbb{8} . \overline{8}$ workshop.

\section{Method}

Preparation of bowel

Pig colon was harvested from the local abattoi $\frac{0}{2}$ cleaned with running water, and cut into $30 \mathrm{~cm}$ lengths. The mesocolon was carefully removed and the prepared bowel segments immediately stored in normal saline at 4 degrees Celsius. All anastomoses were performed and tested within 24 hours of harvest.

\section{Equipment required}

a) Clear perspex rectangular fish tank

b) Venous pressure manometer set on simple stand

c) Extension tubing incorporating a 3 way stopcock

d) Polyfuser 1 litre infusion bag

e) Blood administration set

f) $60 \mathrm{ml}$ syringe

g) $60 \mathrm{ml}$ syringe driver to deliver $20 \mathrm{ml}$ per min

h) Indian ink

i) Doyen bowel clamps - two

j) Linen ties

\section{Measurement of intraluminal leak pressure}

The equipment is assembled as shown in Figure 1. The $\frac{D}{0}$ segment of bowel containing the anastomosis is prepared for immersion in the water bath by inserting the tubing of from the manometer into one end and securing it with a $N$ linen tie. The other end of the bowel is occluded using a N

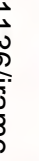




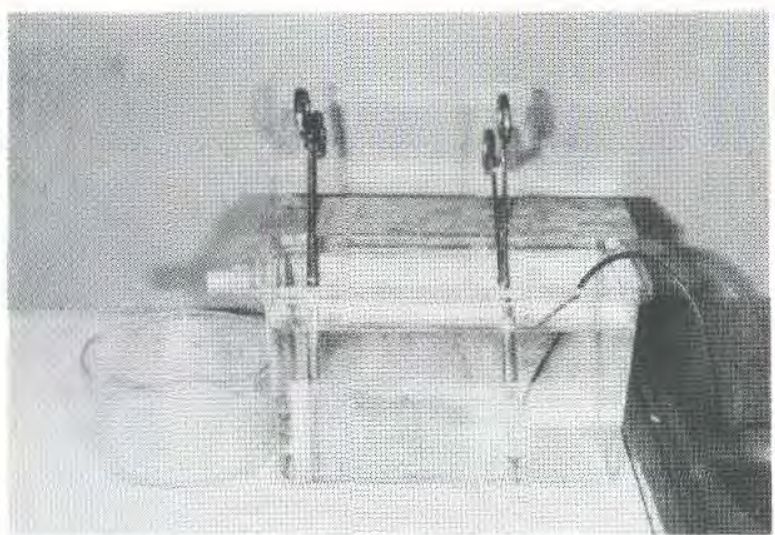

Fig 2. Photograph of anastomosis, immersed in water bath, supported by two Doyen bowel clamps to ensure the whole circumference of the anastomosis can be observed.

Doyen clamp and the second clamp is placed over the linen tie so that the bowel can be suspended in the water bath between these two clamps (Fig 2). Twenty mls of Indian ink are added to each litre of infusion fluid to colour the infusion. The $60 \mathrm{ml}$ syringe in the syringe driver can be filled from the infusion bag via the three way tap and the infusion bag is raised to about $90 \mathrm{cms}$ using the manometer. The bowel is filled from the infusion bag by turning the manometer tap, the manometer reading will fall, whilst the empty bowel is filling. Immediately the manometer reading starts to rise, indicating generation of intraluminal pressure, the syringe driver is switched on and the infusion switched off. Controlled inflation at $20 \mathrm{mls}$ per min produces a slow rise in intraluminal pressure whilst the anastomosis is observed for the first sign of leakage. Low pressure ooze of ink is occasionally seen but failure pressure should be recorded when the first gush of ink is observed to exit under pressure (Fig 3).

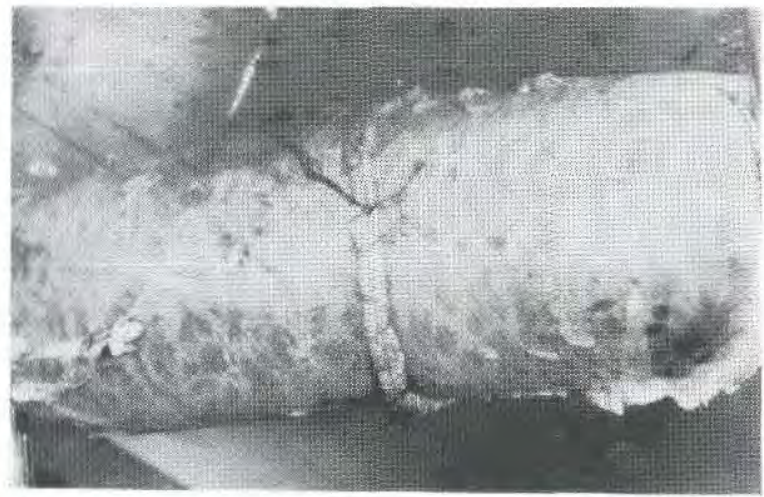

Fig 3. Failure pressure is recorded when ink is observed to emerge under pressure usually manifest by a fine jet $u_{\text {. }}$ ink from a readily identifiable spot as demonstrated in this photograph.

\section{Calculation of failure wall load}

The point of failure can be marked with babcock forceps and the doyen clamps removed from the bowel. The empty bowel is then removed from the water bath and the anastomosis excised with a $1 \mathrm{~cm}$ cuff of normalo bowel each side. The ring of bowel containing the anastomosis is opened and laid flat allowing inspection of the intraluminal aspect of the anastomosis which mays reveal a technical failure at the point of leakage. The circumference of the anastomosis is measured directly using a ruler on the opened specimen which should be gently pulled into a straight line.

The wall load (force/unit length) in a tube of finiten wall thickness is calculated by multiplying the intraluminal pressure by the radius of the tube. The radius of a circle is equal to the circumference divided by a constant and is therefore directly proportional to the circumference.

Wall load, in arbitrary units, can be calculated by multiplying intraluminal pressure by circumference This method of deriving wall tension does not attempt to provide an absolute measurement of circular wall stress tension; it is designed to give a quick, simple way comparing the performance of anastomoses of differ diameter.

\section{Results}

Table 1 shows the results obtained from testing anastomoses performed by the author to standardise equipment. Half the anastomoses were created using to Gambee suture technique with $3 / 0$ vicryl sutures and

Table 1

Leak Pressure - Anastomoses Performed by Auth

\begin{tabular}{|c|c|c|c|c|}
\hline No. & $\begin{array}{c}\text { Type } \\
\text { of } \\
\text { Anastomosis }\end{array}$ & $\begin{array}{c}\text { Leak } \\
\text { Pressure } \\
\text { (cms of } \\
\text { water) }\end{array}$ & $\begin{array}{l}\text { Circum- } \\
\text { ference } \\
\text { (Centi- } \\
\text { metres) }\end{array}$ & $\begin{array}{c}\text { Circular } \\
\text { Wall load } \\
\text { (Arbitrary } \\
\text { units) }\end{array}$ \\
\hline 1 & Sutured & 21.5 & 14.0 & 301 \\
\hline 2 & Sutured & 34.8 & 9.1 & 317 \\
\hline 3 & Sutured & 21.5 & 16.8 & 361 \\
\hline 4 & Sutured & 39.8 & 13.7 & 545 \\
\hline 5 & Sutured & 38,8 & 14.7 & 570 \\
\hline 6 & Stapled & 85.4 & 11.6 & 991 \\
\hline 7 & Stapled & 57.2 & 18.4 & 1052 \\
\hline 8 & Stapled & 97.0 & 11.2 & 1086 \\
\hline 9 & Stapled & 100.0 & 11.9 & 1190 \\
\hline 10 & Stapled & 80.9 & 16.3 & 1319 \\
\hline
\end{tabular}

Intraluminal leak pressure, Anastomotic circumferenceo and derived circular wall load for 10 anastomoses performed by the first author, on fresh pig colon, tog standardise the equipment. Sutured anastomoses per formed using Gambee technique with $3 / 0$ vicryls Autosuture premium $35 \mathrm{~W}$ disposable skin stapler used for skin staple technique described by Fackler (9). 
Table 2

Anastomatic Leak Pressure - Workshop of 8 Students

\begin{tabular}{cccc}
\hline Student & $\begin{array}{c}\text { Leak } \\
\text { pressure } \\
\text { (cms of } \\
\text { water) }\end{array}$ & $\begin{array}{c}\text { Circumference } \\
\text { (centimetres) }\end{array}$ & $\begin{array}{c}\text { Circular } \\
\text { Wall load } \\
\text { (Arbitrary } \\
\text { units) }\end{array}$ \\
\hline 7 & 0 & 0 & 0 \\
5 & 8.3 & 14.2 & 118 \\
4 & 11.0 & 14.2 & 157 \\
1 & 13.5 & 16.5 & 223 \\
6 & 24.2 & 17.0 & 411 \\
8 & 40.5 & 15.5 & 628 \\
3 & 69.5 & 12.5 & 869 \\
2 & 90.5 & 11.7 & 1059 \\
\hline
\end{tabular}

Intraluminal leak pressure, anastomotic circumference and derived circular wall load for 8 skin stapled anastomoses on fresh pig colon performed by military operating theatre staff after watching a 20 minute video presentation introducing the technique.

other half were fashioned using Autosuture's premium $35 \mathrm{~W}$ disposable skin staples according to a technique previously described by Fackler (9).

All anastomoses were observed to fail at stitch or staple insertion holes except numbers $1,2,7$ and 10 . Number 1 failed at a serosal tear caused by overtightening of a suture. Number 2 failed in between two sutures where a tenia coli crossed the anastomotic line. Number 7 failed in between two staples placed $7 \mathrm{~mm}$ apart and where inversion of the serosa was incomplete on inspection of the lumen. Number 10 anastomosis remained intact but the bowel wall failed away from the staple line.

Table 2 shows the results from a 'Dress Rehearsal' for the anastomotic workshop study where 8 military operating theatre staff were shown a 20 minute video demonstrating the skin stapled colonic anastomotic technique and immediately invited to perform an anastomosis on fresh pig colon. Student 2 was a surgeon with previous experience of skin stapled anastomosis whose anastomosis was as good as the first author's. Student 7 succeeded in picking up the opposite wall of the bowel with stay sutures and created an anastomosis without a lumen! Student 8 produced a macroscopically sound anastomosis which leaked at multiple staple insertion holes which represented 'heavy handedness' with the staple gun. All other students had technical flaws in their anastomoses, the most common being failure to invert adequately the serosa at some point; although the quality of student 3's anastomosis appears satisfactory despite this flaw.

\section{Discussion}

Assessment of anastomotic integrity during surgery can be performed using air insufflation whilst the

anastomosis is immersed thus demonstrating the absence of an air leak. Anastomotic failure pressure is often $?$ measured during research on intestinal healing. The clinical method provides a good subjective assessment of 3 integrity whilst the laboratory method involves accurate $\stackrel{\mathbb{Q}}{\complement}$ measurement of an easily reproducible end point. $O$ Assessment of anastomotic quality in an educational음 setting should combine the accurate measurement of a clinically relevant end point with the ability subjectively $\overrightarrow{\vec{F}}$ to observe the performance of the anastomosis to $\frac{D}{9}$ controlled stress.

When comparing anastomoses, simple intraluminal $\frac{\bar{c}}{\bar{D}}$ failure pressure does not take into account differences in $\frac{\vec{\sigma}}{\sigma}$ bowel diameter. The circular wall load produced by a $\propto$ given intraluminal pressure is proportional to the radius के of the anastomosis. Calculation of the circular wall load $\overrightarrow{0}$ at the point of anastomotic leakage provides $a-$ measurement of performance that can be used to $\vec{\omega}$ compare anastomoses performed on bowel of different diameters.

The method designed for our study produces accurate data without resorting to complex, expensive laboratory $\vec{\omega}$ equipment and allows critical inspection of the anastomosis after its 'quality' has been determined. The equipment is simple, economic and portable allowing quality assessment to be performed at any anastomotico workshop.

Anastomosis workshops are considered to be go surgical education by trainees who attend them but cam be formidable undertakings for the organisers $(10,1)$ Performance is usually based on subjective assessment by an instructor or not infrequently left to the trainee make up his own mind. Subjective assessment does net always demonstrate technical flaws as shown in the study. Objective assessment increases the education benefit and was observed to instil an element of competition which should improve performance. Incorporation of regular craft workshops into a surgical $\stackrel{\square}{\square}$ department's postgraduate teaching program would $\Rightarrow$ allow surgical tutors to monitor the progress of trainees. $\frac{9}{3}$ This study demonstrates the feasibility of setting up Inhouse anastomotic workshops and describes a simple effective method of quality assessment.

\section{REFERENCES}

1. Kirby N G, Blackburn G. Field surgery pocket book. HMSO 1981.

2. Burch J M, MARTiN R, Richardson R J, 兰 Muldowny D S, Mattox K L, JoRdan G L.? Evolution of the treatment of the injured colon in $\frac{5}{3}$ the 1980's. Arch Surg 1991; 126: 979-4.

3. BAKER L W, THOMSON S R. The current status of the management of civilian injuries to the colon. Surg Annu 1991; 23: 203-23.

4. Wetherall A P, CoOper G J, Ryan J M, Taylor D E M, Howell G P, Rice P. Use of disposable skin o staplers for bowel anastomosis to reduce laparotomy time in war. Ann $R$ Coll Surg Engl ज্ $1992 ; 74: 200-4$ 
5. Nelson T S, Anders C J. Dynamic aspects of small intestinal rupture: anastomotic strength. Arch Surg 1966; 93: 309-12.

6. HAWLeY P R. The aetiology of colonic anastomotic leaks with reference to collagenase. MS Thesis (London) 1969.

7. Jiborn H, Ahonen J, Zederfeld B. Healing of experimental colonic anastomoses: Bursting strength after left colon resection and anastomosis. Am J Surg 1978; 136: 587-4.

8. Beven P G. Craft workshops in surgery. Br J Surg
1986; 73: $1-2$.

9. Fackler M, Breteau J. Perforating wounds of the abdomen by the modern assault rifle. $J$ Traum (CHINA) Suppl 1990; 6: 192-9.

10. Stotter A, Becket A J, Hansen J P R Capperauld I, Dudley H A F. Simulation in sur gical training using freeze dried material. BrJ Surg 1986; $73: 52-4$

11. Steele R J C, Logie J R C, Munro A. Technica: training in surgery: the trainee's view. $B r J$ Surg? 1989; 76: 1291-3. 